\title{
Journal of \\ Materials Chemistry C
}

\section{Accepted Manuscript}

This article can be cited before page numbers have been issued, to do this please use: T. Zou, X. Wang,

H. Ju, Q. wu, T. Guo, W. Wu and H. Wang, J. Mater. Chem. C, 2018, DOI: 10.1039/C7TC04663D.

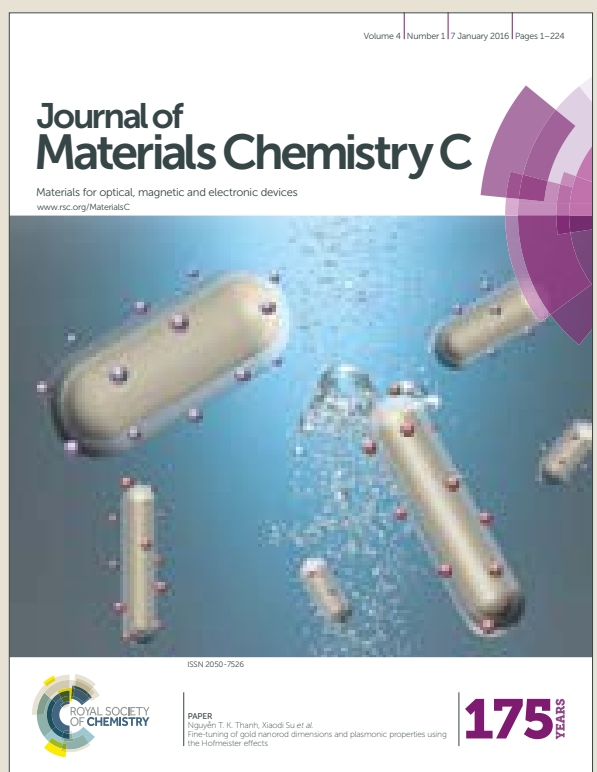

This is an Accepted Manuscript, which has been through the Royal Society of Chemistry peer review process and has been accepted for publication.

Accepted Manuscripts are published online shortly after acceptance, before technical editing, formatting and proof reading. Using this free service, authors can make their results available to the community, in citable form, before we publish the edited article. We will replace this Accepted Manuscript with the edited and formatted Advance Article as soon as it is available.

You can find more information about Accepted Manuscripts in the author guidelines.

Please note that technical editing may introduce minor changes to the text and/or graphics, which may alter content. The journal's standard Terms \& Conditions and the ethical guidelines, outlined in our author and reviewer resource centre, still apply. In no event shall the Royal Society of Chemistry be held responsible for any errors or omissions in this Accepted Manuscript or any consequences arising from the use of any information it contains. 


\section{Table of Contents Entry}

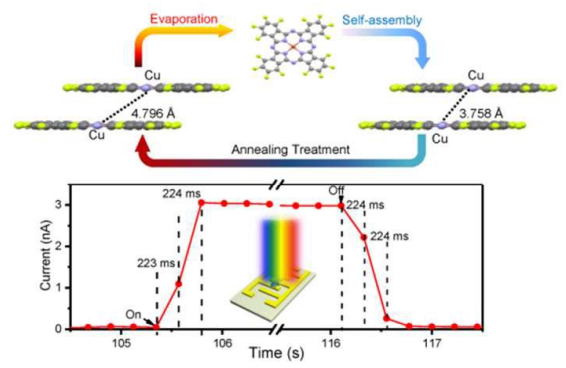

A new polymorph of $\mathrm{F}_{16} \mathrm{CuPc}$ nanowires, the $\eta$ phase, were fabricated for fast response and high sensitivity Visible-NIR photo-detector 


\title{
Journal of Materials Chemistry C
}

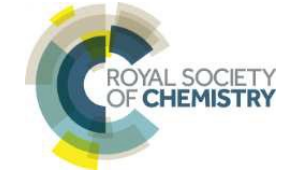

\section{ARTICLE}

Received 00th January 20xx, Accepted 00th January 20xx

DOI: $10.1039 / x 0 x \times 00000 x$

www.rsc.org/

\section{Crystal Structure Tuning in Organic Nanomaterials for Fast Response and High Sensitivity Visible-NIR Photo-detector $\dagger$}

\begin{abstract}
Taoyu Zou ${ }^{\mathrm{a}, \mathrm{d}}$, Xiaoyan Wang ${ }^{\mathrm{a}}$, Haidong Ju${ }^{\mathrm{b}}$, Qiong Wu ${ }^{\mathrm{b}}$, Tingting Guo ${ }^{\mathrm{a}}$, Wei Wu ${ }^{\mathrm{c}, *}, \mathrm{Hai}$ Wang ${ }^{\mathrm{a}, \mathrm{d}, *}$
A new polymorph of copper hexadecafluorophthalocyanine, the $\eta-F_{16} C u P c$, was fabricated via organic vapor phase deposition. The crystal structure, morphology and optical properties of $\eta-F_{16} C u P c$ were characterized by $X$-ray diffraction, scanning electron microscopy, Fourier-transformed infrared spectroscopy and UV-Vis spectroscopy. Moreover, the phase transitions of $F_{16} \mathrm{CuPc}$ from the $\eta$ - to the $\beta$-phase were investigated by thermogravimetric analysis (TGA) and differential scanning calorimetry. In addition, the visible-NIR photodetectors based on $\mathrm{F}_{16} \mathrm{CuPc}$ nanowires were fabricated and their photo-response features were systematically studied. The absorption spectra of the $\eta-F_{16} C u P c$ exhibited a broad band in the visible and near-infrared (NIR) regions, extending to a wavelength of $\sim 900 \mathrm{~nm}$. The $n-\mathrm{F}_{16} \mathrm{CuPc}$ photodetector exhibited fast response even at a low bias voltage of $0.5 \mathrm{~V}$ under a solar simulator with a power of $100 \mathrm{~mW} \mathrm{~cm}^{-2}$. The photocurrent response rise/fall time of photodetectors was $~ 448 \mathrm{~ms}$ under various irradiation wavelengths. This organic-based photodetectors also performed well for near-infrared light with wavelength up to $940 \mathrm{~nm}$.
\end{abstract}

\section{Introduction}

Recently small molecules have been widely employed in the applications of organic light-emitting diode (OLED), ${ }^{1}$ organic photovoltaics (OPV), ${ }^{2}$ organic field-effect transistor (OFET), ${ }^{3-5}$ gas sensors, ${ }^{6,7}$ as well as photosensitizers for photodynamic therapy, etc. ${ }^{8}$ Crystal structures and molecular orientations have a significant effect on the optoelectronic and magnetic properties in crystalline materials. One of the most significant advantages for organic materials is the ease to tune their properties by regulating crystal structures, in particular, the inter-molecular distance. As an example, Metalphthalocyanines (MPcs), a $\pi$-conjugated system on an aromatic organic ring, exhibit excellent tunable physicochemical and thermal properties by controlling their crystal structures and morphologies. MPcs have two types of common crystal structures, namely the $\alpha$ - and $\beta$-forms, in which molecular chains are normally formed normally along the $b$ axis. The lattice constant $b$, also the inter-metal distance along the molecular chain, is $\sim 3.8 \AA(\sim 4.8 \AA$ ) for the $\alpha$ - $(\beta-)$ phase, ${ }^{9}$ which is the predominant difference between different

\footnotetext{
a. Key laboratory of Yunnan Provincial Higher Education Institutions for Organic Optoelectronic Materials and Devices, Kunming University, Kunming 650214, China.E-mail: hai.wang.ucl@gmail.com

b. Department of Chemical Science and Technology, Kunming University, 650214, People's Republic of China.

Department of Physics and Astronomy and London Centre for Nanotechnology University College London, Gower Street, London WC1E 6BT, United Kingdom Email:wei.wu@ucl.ac.uk

d. Kunming DeepLand Nanomaterial Research Institute, Yunnan Ocean Organic Optoelectronic Technology Ltd.

† Electronic Supplementary Information (ESI) available: The fitted XRD results of $\eta$ $\mathrm{F}_{16} \mathrm{CuPc}$ and photo response characteristics of the photodetector device. See DOI: $10.1039 / \times 0 \times x 00000 x$
}

types of phases. For instance, $\mathrm{X}$. He et al. recently reported the improvement of free-carrier transport properties in highly crystalline $\alpha$-ZnPc film by reducing the inter-Zn distance of $\sim 0.1$ $\AA .{ }^{10} \mathrm{Wu}$ and co-workers revealed the relationship between the magnetic properties and the stacking geometry of the phthalocyanine molecules and found strong antiferromagnetic coupling (within organic semiconductors) with an exchange energy of $\sim 100 \mathrm{~K}$ in the $\alpha$-CoPc, even higher with reduced CoCo distances. ${ }^{11,12}$ In addition, a new stable form of CuPc with small lattice spacing and hence large electronic overlaps, namely the n-CuPc, has shown a broader optical absorption spectrum than the other crystal structures of CuPc. ${ }^{13}$

Copper hexadecafluorophthalocyanines $\left(\mathrm{F}_{16} \mathrm{CuPc}\right)$, as airstable $\mathrm{n}$-type organic semiconductors, have been widely applied in OLED, ${ }^{14}$ OFET $^{15}$ and organic solar cells, ${ }^{16}$ owing to their excellent electrical and optical properties, such as a relatively high mobility of $0.6 \mathrm{~cm} 2 \mathrm{~V}-1 \mathrm{~s}-1$ and broad optical absorption spectrum compared to other organic semiconductors. ${ }^{17-20}$ What is more important is that, compared with $\mathrm{CuPc}$, these outstanding properties mainly stem from a shorter $\pi-\pi$ stacking inter-molecular-plane distance ( 3.25 $\AA$ ) in $\mathrm{F}_{16} \mathrm{CuPc}$, yet that of MPc is $3.4 \AA \AA^{9,21}$

Recently much effort has been made to optimize the crystal structure and morphology of $\mathrm{F}_{16} \mathrm{CuPc}$ to improve the device performance. Oteyza, et al. discovered that the increasing of film thickness caused a structural transition of $\mathrm{F}_{16} \mathrm{CuPc}$ film from the $\beta$-bilayer to the $\beta$-form. ${ }^{22}$ Yoon, et al. determined the single-crystal structure of $\mathrm{F}_{16} \mathrm{CuPc}$ ribbons, which crystallized in triclinic space group rather than monoclinic. ${ }^{15,23}$ In the study by Pandey, et al., the structures of both the $\mathrm{F}_{16} \mathrm{CuPc}$ thin film on graphene oxide and the single crystal are resolved, which exhibited a brick-stacking structure. 
Despite the success on the determination of $\mathrm{F}_{16} \mathrm{CuPc}$ structure, the previous research from different groups found a similar Cu-Cu distance, which is $\sim 4.8 \AA$, although other parameters are different. We have been thus motivated to further explore the crystal structure of $\mathrm{F}_{16} \mathrm{CuPc}$ to achieve a smaller $\mathrm{Cu}-\mathrm{Cu}$ distance, hence improving the photoelectric properties. Organic nanowires are one of the promising choices as shown in the previous work. ${ }^{13,24}$ Although $\mathrm{F}_{16} \mathrm{CuPc}$ nanowires have been synthesized in recent works, ${ }^{16,25}$ so far, none of their crystal structures have thoroughly been identified.

In this work, a detailed investigation of $\mathrm{F}_{16} \mathrm{CuPc}$ nanowires, the $\eta$ phase, is presented with the aim to address the above issues. $\mathrm{F}_{16} \mathrm{CuPc}$ nanowires were fabricated by organic vapor phase deposition (OVPD). Our X-ray diffraction (XRD) results reveal that $F_{16} \mathrm{CuPc}$ nanowires (herringbone stacking) possess a monoclinic unit cell with $a=16.360 \AA, b=3.758 \AA, c=29.123$ $\AA, \beta=121.6^{\circ}$. Hence, owing to the reduction of the $\mathrm{Cu}-\mathrm{Cu}$ distance, a larger spatial $\pi-\pi$ overlap is expected to be present in $\mathrm{F}_{16} \mathrm{CuPc}$ nanowires, which may improve the carrier mobility, facilitating a high performance in electrical devices. Moreover, we report the phase transition of $F_{16} \mathrm{CuPc}$ crystal from the $\eta$ - to $\beta$-phase by annealing treatment. Furthermore, the photodetector based on $\eta-F_{16} C u P c$ nanowires was fabricated and the performance to respond to visible and near-infrared (NIR) light was systematically investigated. The following discussions fall into three sections: in §ll we introduce experimental and computational details, in §III we present and discuss our results, and finally in §IV, we draw some general conclusions.

\section{Experimental and Theoretical Section}

Fabrication of $\mathrm{F}_{16} \mathrm{CuPc}$ crystals and photodetector devices

$\mathrm{F}_{16} \mathrm{CuPc}$ powders, purchased from Tokyo Chemical Industry, were loaded in a quartz tube. The quartz tube was then put in a single-zone heating furnace, keeping the powders in the middle of the furnace. Ambient air was flushed out by $\mathrm{N}_{2}$ gas (99.999\%) at a rate of 400 standard cubic centimeters per minute $(\mathrm{sccm})$ for $30 \mathrm{~min}$ before heating the $\mathrm{F}_{16} \mathrm{CuPc}$ powders. After that, $\mathrm{F}_{16} \mathrm{CuPc}$ nanowires and needle-like $\mathrm{F}_{16} \mathrm{CuPc}$ crystals were prepared by vaporizing $\mathrm{F}_{16} \mathrm{CuPc}$ powders at a series of precursor temperatures, $450{ }^{\circ} \mathrm{C}, 460{ }^{\circ} \mathrm{C}, 480^{\circ} \mathrm{C}, 500{ }^{\circ} \mathrm{C}$ and $520^{\circ} \mathrm{C}$, respectively, for $300 \mathrm{~min}$, at a flow rate of $400 \mathrm{sccm}$. $\mathrm{F}_{16} \mathrm{CuPc}$ ribbons were deposited on the high -temperature area, while $\mathrm{F}_{16} \mathrm{CuPc}$ nanowires were deposited at the roomtemperature area. Annealing treatment on the as-prepared $\mathrm{F}_{16} \mathrm{CuPc}$ nanowire was carried out to demonstrate the phase transition. $\mathrm{F}_{16} \mathrm{CuPc}$ nanowires were annealed using a singlezone heating furnace under vacuum condition ( $\sim 2 \mathrm{~Pa})$ at a series of temperatures $\left(60^{\circ} \mathrm{C}, 70^{\circ} \mathrm{C}, 80^{\circ} \mathrm{C}, 100^{\circ} \mathrm{C}, 200{ }^{\circ} \mathrm{C}, 250\right.$ ${ }^{\circ} \mathrm{C}, 260{ }^{\circ} \mathrm{C}, 270{ }^{\circ} \mathrm{C}, 280{ }^{\circ} \mathrm{C}, 300{ }^{\circ} \mathrm{C}$ to $400{ }^{\circ} \mathrm{C}$ ). Photodetector devices were fabricated by attaching as-prepared nanowire cluster onto the gold interdigitated electrodes, which were wetted by a few drops of alcohol to improve the contact with nanowires. The devices were then placed in a vacuum drying oven at $40^{\circ} \mathrm{C}$ for 12 hours to remove the solution.

\section{Characterization of $\mathrm{F}_{16} \mathrm{CuPc}$ crystals and Photodetector devices}

The morphology was measured using a scanning electron microscope (SEM, HITACHI 3400N). The analysis of the elemental compositions was obtained from energy-dispersive spectroscopy (EDS) (EDAX). The crystal structures of $\mathrm{F}_{16} \mathrm{CuPc}$ were measured by means of XRD using $\mathrm{Cu} K \alpha(\lambda=0.154056$ $\mathrm{nm}$ ) (Rigaku, TTR III). X-ray photo-electron spectroscopy (XPS) measurements were performed by using a PHI5000 Versa Probe electron energy analyzer. The properties of chemical bonds were determined by a Fourier-transformed infrared (FTIR) spectrophotometer (Agilent Technologies, Cary 600 Series). To obtain the optical absorption spectra, $\mathrm{F}_{16} \mathrm{CuPc}$ nanowires, ribbons and powders were slightly milled on the quartz substrate and then measured by a UV-Vis spectrometer (Hitachi, U-4100). The phase transition of the $\mathrm{F}_{16} \mathrm{CuPc}$ nanowires was investigated by thermogravimetric analysis (TGA) and differential scanning calorimetry (DSC) (METTLER TOLEDO, STARe System). The $I-V$ curves and photo response characteristics of the photodetector were measured using a Keithley 2400 source meter (Keithley Instruments Inc. USA).

\section{Computational details}

We have carried out first-principles calculations for the excited states of isolated $\mathrm{F}_{16} \mathrm{CuPc}$ molecule and dimers based on density-functional theory, using hybrid-exchange density functional, B3LYP, ${ }^{26}$ with a 6-31G basis set in the Gaussian 09 code. $^{27,28}$ The reviews of TDDFT formalism and applications can be found in Reference. ${ }^{29}$ The advantages of B3LYP include a partial elimination of self-interaction errors and a balancing of the tendencies to delocalize and localize one-electron wavefunctions by mixing Fock exchange with that from a generalized gradient approximation (GGA) exchange functional. ${ }^{26}$ B3LYP functional has previously been shown to provide an accurate description of the electronic structure and magnetic properties for both inorganic and organic compounds. ${ }^{11,12,24,30-34}$ Time-dependent density function theory (TDDFT) was used here to calculate the excitation energies of the single molecule and dimers (extracted from the $\beta$ - and $\eta$-phase $F_{16} \mathrm{CuPc}$ ) to compare with the experimental spectra. $^{35,36}$

\section{Results and discussion}

\section{Morphology and Chemical composition analysis}

Fig. 1 shows the morphology and transition of $\mathrm{F}_{16} \mathrm{CuPc}$ crystalline material. $\mathrm{F}_{16} \mathrm{CuPc}$ nanowires were obtained through OVPD process using ribbon-like powders. The average width of blue $\mathrm{F}_{16} \mathrm{CuPc}$ nanowires is $\sim 60 \mathrm{~nm}$ and the length of the wires is approximately a few microns. Moreover, large size of purple ribbon-like $\mathrm{F}_{16} \mathrm{CuPc}$ crystal with the length of $\sim 2 \mathrm{~cm}$ was also fabricated in the high- temperature zone, as shown in Fig. S1 $(\mathrm{ESI}+)$, which is similar to those in the previous studies. ${ }^{19,} 23$ Morphology transition from nanowires to nanoribbons occurred when increasing the annealing temperature, as shown in Fig. 1(c)-(f). When the annealing temperature is below $200{ }^{\circ} \mathrm{C}$, the cluster is nanowires, whereas nanoribbon- 
like crystals can be found at $300{ }^{\circ} \mathrm{C}$ and became dominant as the temperature rises to $400{ }^{\circ} \mathrm{C}$. This clearly indicates that $\mathrm{F}_{16} \mathrm{CuPc}$ crystals include two different morphologies, nanowires and nanoribbon, corresponding to the $\eta$ - and $\beta$ phases; their crystal structures will be further discussed below. By systematically regulating experimental parameters, including heating temperature, the flow rate of carrier gas and especially the ambient and annealing temperatures the fabrication of $\mathrm{F}_{16} \mathrm{CuPc}$ nano/micron wires and ribbons can be controlled. ${ }^{23,37}$
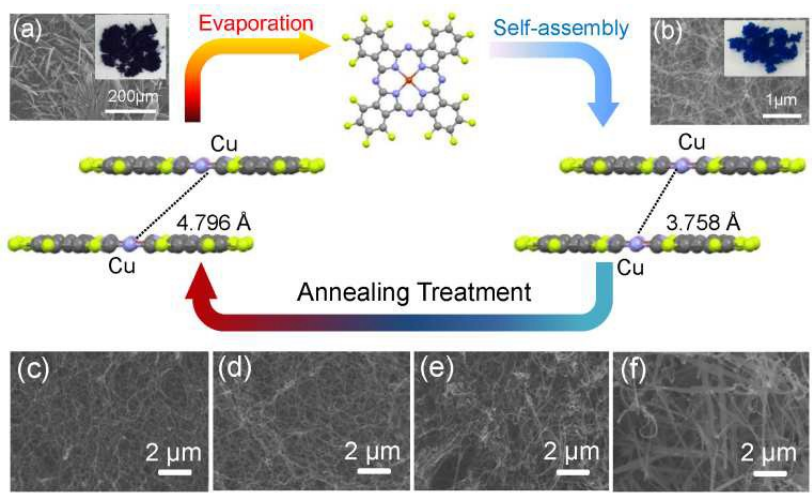

Fig. 1 In (a) and (b), SEM images of $F_{16} \mathrm{CuPc}$ powders and nanowires are shown, and insets are $\mathrm{F}_{16} \mathrm{CuPc}$ powders (a) and nanowires (b). The morphology transition from nanowires to nanoribbons along with an increasing annealing temperature: (c) $100{ }^{\circ} \mathrm{C}$, (d) $200{ }^{\circ} \mathrm{C}$, (e) $300{ }^{\circ} \mathrm{C}$, (f) 400 ${ }^{\circ} \mathrm{C}$, respectively.

The EDS spectrum in Fig. S2 (ESIt) indicates the existence of $\mathrm{C}, \mathrm{N}, \mathrm{F}$ and $\mathrm{Cu}$ elements in the $\mathrm{F}_{16} \mathrm{CuPc}$ nanowires. To further confirm the constituent elements and the valence states in $\mathrm{F}_{16} \mathrm{CuPc}$, XPS measurement was carried out to study the chemical composition as shown in Fig. 2(a)-(d). In Fig. 2(a) for the XPS survey scan of $\mathrm{F}_{16} \mathrm{CuPc}$ nanowires, these identified peaks reinforce the effectiveness of our EDS analysis. For the high-resolution XPS spectra of Cu $2 p$ (Fig. 2(b)), two peaks at $935.7 \mathrm{eV}$ and $955.5 \mathrm{eV}$ are due to $\mathrm{Cu} 2 p_{3 / 2}$ and $2 p_{1 / 2}$, respectively. The satellite peak appears at higher binding energy $\sim 944 \mathrm{eV}$, indicating the existence of $\mathrm{Cu}^{2+}$ ions in $\mathrm{F}_{16} \mathrm{CuPc}$ molecule. ${ }^{38,39}$ By separating the core level of $\mathrm{C} 1 \mathrm{~s}$ peak (see Fig. 2(c)), four peaks can be drawn centered at $284.51 \mathrm{eV}$ (P1), $285.7 \mathrm{eV}$ (P2), $287.11 \mathrm{eV}$ (P3) and $288.1 \mathrm{eV}$ (P4), which indicated four different bonds of carbon atoms in $\mathrm{F}_{16} \mathrm{CuPc}$ molecule. The strongest peak, $\mathrm{P} 1$, can be attributed to the $\mathrm{C}-\mathrm{C}$ bond in the benzene rings. $\mathrm{P} 2$ is assigned to the $\mathrm{C}-\mathrm{C}$ bond of aromatic carbon atoms in the organic ring, ${ }^{40}$ while $\mathrm{P} 3$ is most likely related to $\mathrm{C}-\mathrm{N}$ bond. ${ }^{41} \mathrm{P} 4$ is due to the C-F bond. ${ }^{42}$ Two peaks at $399.11 \mathrm{eV}$ and $399.91 \mathrm{eV}$, for the high-resolution spectra of $\mathrm{N} 1 s$ in Fig. 2(d), correspond to the bonds of the four inner most nitrogen atoms with the central copper ion and of outer most nitrogen with carbon atoms. ${ }^{38,43}$

Moreover, the FTIR spectra of $\mathrm{F}_{16} \mathrm{CuPc}$ nanowires, ribbons and powders are shown in Fig. 2(e). The peaks at $1272 \mathrm{~cm}-1$ and $1320 \mathrm{~cm}-1$ correspond to the $\mathrm{C}=\mathrm{N}-\mathrm{C}$ at bridge sites while the peak at $1151 \mathrm{~cm}^{-1}$ can be assigned to $\mathrm{Cu}-\mathrm{N}$ bonding. ${ }^{44,45} \mathrm{It}$ should be noted that the peak shifts at $962 \mathrm{~cm}^{-1}, 1151 \mathrm{~cm}^{-1}$,
$1272 \mathrm{~cm}^{-1}, 1525 \mathrm{~cm}^{-1}$ are significantly affected by the structural change.

The characteristic peaks of as-prepared $\mathrm{F}_{16} \mathrm{CuPc}$ ribbons and nanowires are consistent with those of $F_{16} \mathrm{CuPc}$ powders. Thus, by analyzing the XPS and FTIR spectra, these results manifest that the structures of individual molecules in $\mathrm{F}_{16} \mathrm{CuPc}$ ribbons and nanowires remain almost the same as that of the $\mathrm{F}_{16} \mathrm{CuPc}$ powders after high-temperature vapor deposition process.
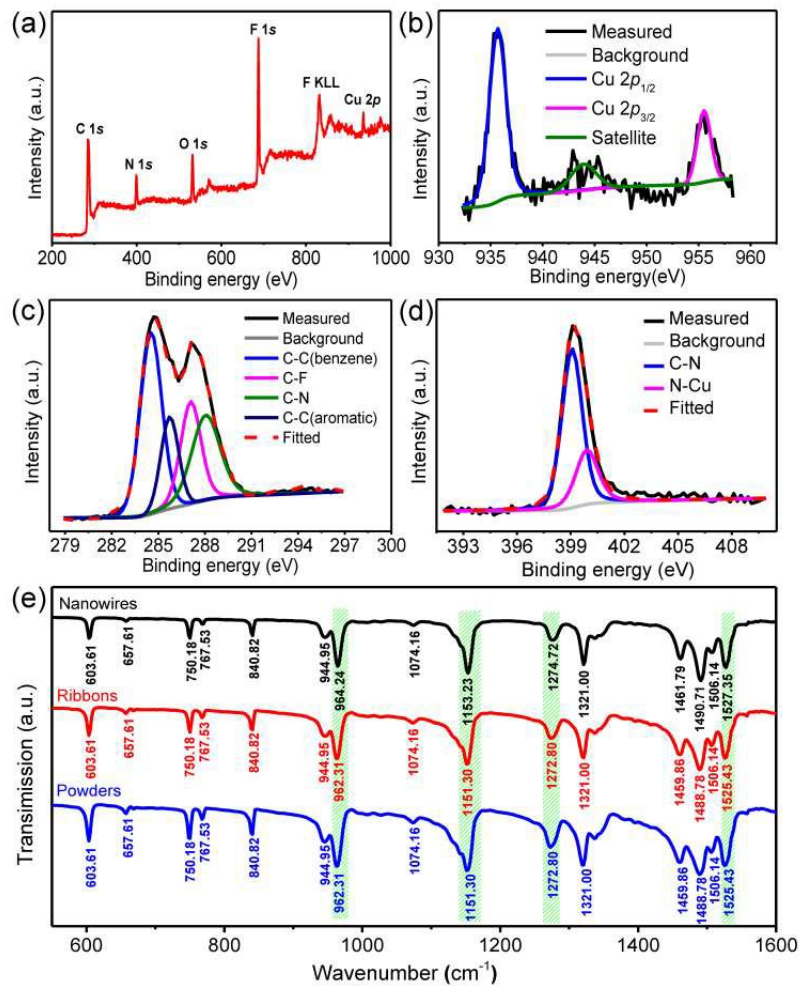

Fig. 2 Top view and cross-section (insets) SEM images of CuPc nano columns on quartz as function of growth time (t), (a) $2 \mathrm{~min}$, (b) $5 \mathrm{~min}$, (c) $10 \mathrm{~min}$, (d) $20 \mathrm{~min},(\mathrm{e}) 30 \mathrm{~min}$ and (f) $60 \mathrm{~min}$, respectively.

\section{Crystal structure analysis}

The XRD pattern of $\mathrm{F}_{16} \mathrm{CuPc}$ nanowires is shown in Fig. 3(a). The corresponding parameters for the unit cell are listed in Table 1, along with those in the previous works. The unit cell parameters obtained by fitting the XRD patterns with the MDI JADE 6 program (Materials Data Inc, Liverpool, CA) are $a=$ $16.36 \AA, b=3.758 \AA, c=29.123 \AA, \beta=121.6^{\circ}$; the space group turns out to be monoclinic (P2). Fig. S3 (ESI + ) shows a good agreement between the experimental and fitted curves for $\mathrm{F}_{16} \mathrm{CuPc}$ nanowires with a Residual Error of Fit $(\mathrm{R})$ of $2.78 \%$. The calculated peaks are consistent with experimental results; Table S1 gives the comparison between the fitted and calculated diffraction peaks and the interplanar distances $d$, as well as the corresponding lattice planes for $\mathrm{F}_{16} \mathrm{CuPc}$ nanowires. The lattice parameters of $\mathrm{F}_{16} \mathrm{CuPc}$ nanowires reveal that the $\mathrm{F}_{16} \mathrm{CuPc}$ nanowires should possess a herringbone-type packing structure, as shown in Fig. 3(b) and (c). 


\section{ARTICLE}

The main peaks of $\mathrm{F}_{16} \mathrm{CuPc}$ nanowires at $2 \theta=6.34^{\circ}(\mathrm{d}=$ $13.93 \AA$ ) $, 6.60^{\circ}(d=13.38 \AA), 7.04^{\circ}(d=12.55 \AA)$ and $27.74^{\circ}(d$ $=3.21 \AA$ ) correspond to the (100), (-102), (002) and (014) planes, respectively. XRD patterns of $\mathrm{F}_{16} \mathrm{CuPc}$ ribbons and of $\mathrm{F}_{16} \mathrm{CuPc}$ powders in Fig. $3(\mathrm{a})$ and (b) show only one dominant peak at $6.12^{\circ}$, which is related to the (002) plane, in a good agreement with previous experimental results and the crystal structure model proposed by Yoon et al. ${ }^{15,23}$ The other significant peaks for $\mathrm{F}_{16} \mathrm{CuPc}$ ribbons at $12.26^{\circ}$ and $31.22^{\circ}$ can be attributed to the diffractions of the (004) and (134) planes. By comparing the XRD patterns of $\mathrm{F}_{16} \mathrm{CuPc}$ nanowires, ribbons, powders and those reported in the previous works, we can conclude that the $\mathrm{F}_{16} \mathrm{CuPc}$ nanowires possess a new crystal structure.

Table 1 The crystal structure of F16CuPc in this work along with those reported previously.

\begin{tabular}{|c|c|c|c|c|c|c|}
\hline & $\begin{array}{c}\text { This } \\
\text { work } \\
(\eta)\end{array}$ & $\beta_{1}$ & $\boldsymbol{\beta}_{2}$ & $\boldsymbol{\beta}_{3}$ & $\boldsymbol{\beta}_{4}$ & $\boldsymbol{\beta}_{5}$ \\
\hline $\begin{array}{l}\text { crystal } \\
\text { system }\end{array}$ & $\begin{array}{l}\text { Mono- } \\
\text { clinic }\end{array}$ & $\begin{array}{c}\text { Tricli- } \\
\text { nic }\end{array}$ & $\begin{array}{l}\text { Mono- } \\
\text { clinic }\end{array}$ & $\begin{array}{l}\text { Tricli- } \\
\text { nic }\end{array}$ & $\begin{array}{c}\text { Tricli- } \\
\text { nic }\end{array}$ & $\begin{array}{l}\text { Mono- } \\
\text { clinic }\end{array}$ \\
\hline $\begin{array}{l}\text { Space } \\
\text { group }\end{array}$ & $P 2$ & $P-1$ & & $P-1$ & $P-1$ & $P 21 / c$ \\
\hline$a(\AA)$ & 16.36 & 4.89 & 28.33 & 4.796 & 4.85 & 20.018 \\
\hline$b(\AA)$ & 3.758 & 10.29 & 4.755 & 10.228 & 10.27 & 5.106 \\
\hline$c(\AA)$ & 29.123 & 14.91 & 10.17 & 28.002 & 28.39 & 15.326 \\
\hline$\alpha\left({ }^{\circ}\right)$ & 90 & 74.24 & 90 & 86.41 & 86.61 & 90 \\
\hline$\beta\left({ }^{\circ}\right)$ & 121.6 & 87.22 & 93.17 & 87.89 & 87.88 & 111.83 \\
\hline$\gamma\left(\left(^{\circ}\right)\right.$ & 90 & 80.80 & 90 & 81.39 & 81.70 & 90 \\
\hline Ref. & & {$\left[{ }^{21}\right]$} & {$\left[{ }^{15}\right]$} & {$\left[{ }^{23}\right]$} & {$\left[{ }^{19}\right]$} & {$\left[{ }^{22}\right]$} \\
\hline
\end{tabular}

The shortest lattice constant in the $\mathrm{F}_{16} \mathrm{CuPc}$ nanowires, $\mathrm{b}=$ $3.758 \AA$, which closely matches that of the $\alpha$-CuPc $(b=3.769$ $\AA)^{46}$ and the $\eta$-CuPc $(b=3.77 \AA)^{13}$ and $\mathrm{Cl}_{16} \mathrm{CuPc}(\mathrm{b}=3.76 \AA) .{ }^{47}$ The inter-plane distance between the adjacent molecules within one column is $\sim 3.25 \AA^{21,}{ }^{23}$ Furthermore, the decrease on the lattice constant $b$ indicated the increase of the stacking angle $\left(\omega=60^{\circ}\right)$ between the $b$ axis and the molecular plane, comparing with the previous studies, ${ }^{21,23}$ which could result in a lager $\pi-\pi$ overlap between the adjacent molecules within the chain. The $b$-axis in these $\mathrm{F}_{16} \mathrm{CuPc}$ nanowires was along the nanowires. ${ }^{16}$ As a consequence, higher charge mobility in the nanowires is expected. ${ }^{48,49}$

In addition, the effects of precursor temperatures on the morphology and crystal structures of $\mathrm{F}_{16} \mathrm{CuPc}$ nanowires are further studied as shown in Fig. S4 (ESI $\left.{ }^{+}\right)$. The morphology of
$\mathrm{F}_{16} \mathrm{CuPc}$ remains as flexible nanowire with precursor temperature ranging from $450{ }^{\circ} \mathrm{C}$ to $500{ }^{\circ} \mathrm{C}$. But it is clear that the size of $\mathrm{F}_{16} \mathrm{CuPc}$ nanowires enlarges with increasing precursor temperature. The overall XRD pattern for each $\mathrm{F}_{16} \mathrm{CuPc}$ nanowire in Fig. S4(e) remains the same as well, which implies they have identical crystal form. Moreover, as shown in Fig. S4(e), when the precursor temperature increases, the three distinguishable peaks can be found and become sharper, suggesting that crystallinity of $\mathrm{F}_{16} \mathrm{CuPc}$ nanowires is significantly enhanced.

According to the experimental results, the crystal structure of $\mathrm{F}_{16} \mathrm{CuPc}$ is most significantly influenced by the deposition area temperature. Thus, the possible formation mechanism of $\eta-\mathrm{F}_{16} \mathrm{CuPc}$ can be described as follows: $\mathrm{F}_{16} \mathrm{CuPc}$ molecules come out at the vaporization temperature and then flow downstream to crystallize into small nuclei acting as seeds for the growth of the $\eta-F_{16} \mathrm{CuPc}$ and the $\beta-F_{16} \mathrm{CuPc}$ in the hightemperature and low-temperature zone, respectively. When increasing the heating temperature for the powders and raising the concentration of the $\mathrm{F}_{16} \mathrm{CuPc}$ molecules, these nucleuses grow into nanowire and ribbon structure and the fast formation process of the $\eta-F 16 C u P c$ nanowires and the $\beta$ $\mathrm{F}_{16} \mathrm{CuPc}$ ribbons happens thanks to the van der Waals forces between molecules.

Therefore, from these details, we can infer that $\mathrm{F}_{16} \mathrm{CuPc}$ nanowires with new crystal structure may exhibit enhanced electro-optical properties, thus leading to a high performance in the application of electronic devices such as organic photodetectors.

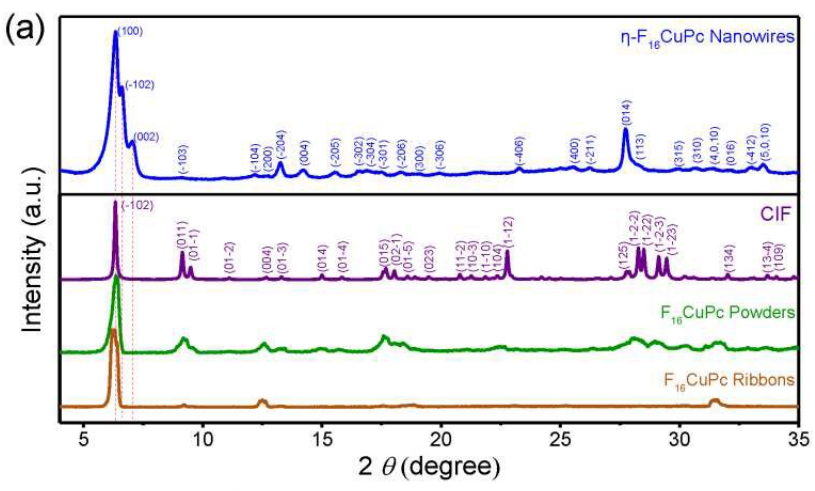

(b)
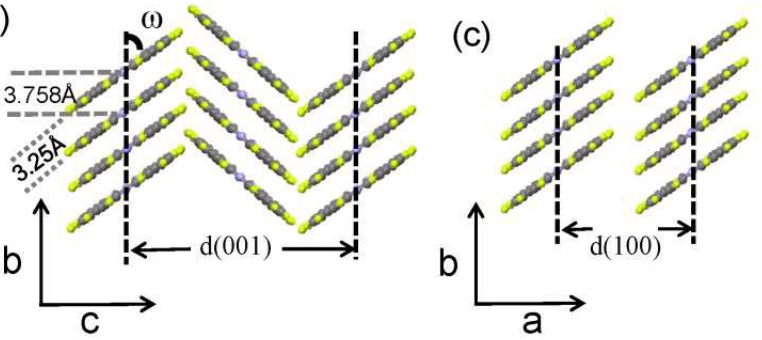

Fig. 3 (a) XRD patterns for as-grown $\mathrm{F}_{16} \mathrm{CuPc}$ nanowires deposited at $520^{\circ} \mathrm{C}$ ribbons and powders are shown, as well as the simulation based on the $\mathrm{CIF}$ files from Yoon et al.. The proposed structure of $\mathrm{F}_{16} \mathrm{CuPc}$ nanowires is viewed along the a-axis shown in (b) and the c-axis (c). 


\section{Structural transitions of $\mathrm{F}_{16} \mathrm{CuPc}$ nanowires}

In order to further understand the structural transition dynamics of $\mathrm{F}_{16} \mathrm{CuPc}$ nanowires, the as-grown $\mathrm{F}_{16} \mathrm{CuPc}$ nanowires with annealing treatment are investigated by XRD and differential scanning calorimetry (DSC) analysis.

From the XRD patterns in Fig. 4(a), we can clearly see three phase-transition steps in the annealing treatment process. When annealing below $70{ }^{\circ} \mathrm{C}$, the $\mathrm{F}_{16} \mathrm{CuPc}$ nanowires remained as the $\eta$-phase with two dominant peaks at $6.30^{\circ}(-101)$ and $27.75^{\circ}(014)$, At annealing temperatures from $80^{\circ} \mathrm{C}$ to $270{ }^{\circ} \mathrm{C}$, the dominant peaks shifted to $6.15^{\circ}$ and $28.16^{\circ}$, corresponding to $(-101)$ and (113) in the $n$-phase. An intermediate phase appeared in the interval of the annealing temperatures between $280^{\circ} \mathrm{C}$ and $300{ }^{\circ} \mathrm{C}$. Once the annealing temperature exceeded $300{ }^{\circ} \mathrm{C}$, the crystal tends to be in the $\beta$-phase with distinguishable peaks at $6.22^{\circ}(002), 9.12^{\circ}(011), 9.41^{\circ}(0-11)$, $12.51^{\circ}(004), 31.70^{\circ}(134)$, which can also be observed in the ribbon-like crystals, as shown in Fig. 1(c) and 1(d).
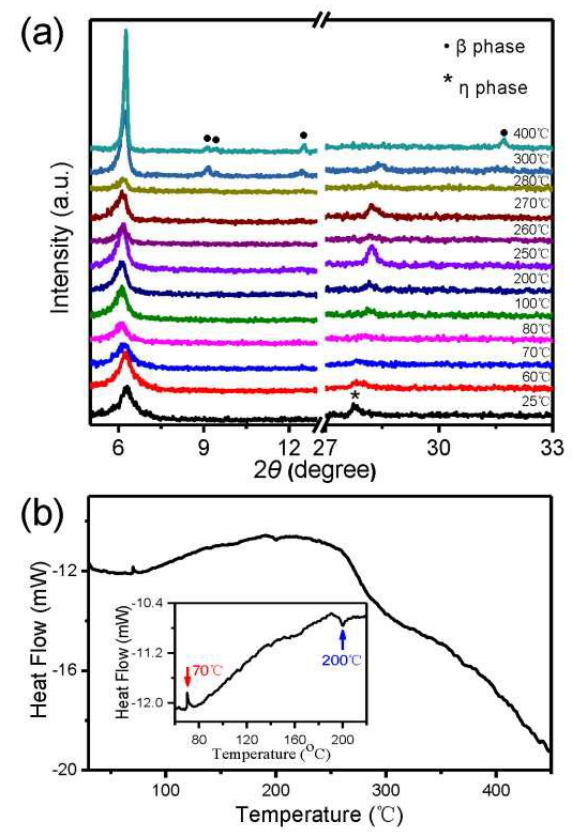

Fig. 4 (a) XRD patterns of as-grown $\mathrm{F}_{16} \mathrm{CuPC}$ nanowires annealed at different temperatures ranging from room temperature up to $400^{\circ} \mathrm{C}$. (b) DSC curves of $\mathrm{F}_{16} \mathrm{CuPc}$ nanowires at a heating rate of $5{ }^{\circ} \mathrm{C} / \mathrm{min}$; the inset includes a peak at $70{ }^{\circ} \mathrm{C}$ and a dip at $200{ }^{\circ} \mathrm{C}$ in the DSC curves.

To illustrate the subtle change of phase transitions, DSC was employed for $\mathrm{F}_{16} \mathrm{CuPc}$ nanowires in Fig. 4(b). A clear exotherm peak at $70{ }^{\circ} \mathrm{C}$ and an endothermic peak at $200{ }^{\circ} \mathrm{C}$ might be due to the variation of molecular orientations in the $\eta$-phase, in agreement with the two feature diffraction peaks at low- and high-temperature regions as revealed in Fig. S5 $(\mathrm{ESI}+)^{\circ}$. The rapid endothermic process at the temperature of $280^{\circ} \mathrm{C}$ indicated the initial stage of the phase transition from the $\eta$ - to the $\beta$-phase. An endothermic peak at $\sim 498^{\circ} \mathrm{C}$ can be ascribed to the phase transition into the $\beta$-phase, as shown in Fig. S6 $(E S I+)$. The XRD pattern of the remaining sample for
$\mathrm{F}_{16} \mathrm{CuPc}$ nanowires after DSC measurements up to $500{ }^{\circ} \mathrm{C}$ is shown in Fig. $S 7$ (ESIt). This reinforces our analysis of the $\beta$ phase. Additional, from the thermogravimetric curve in Fig. S6 $(\mathrm{ESI}+)$, we can see that the $\mathrm{F}_{16} \mathrm{CuPc}$ crystal started to vaporize at $582{ }^{\circ} \mathrm{C}$.

The above has systematically discussed the crystal structure of the $\eta-F_{16} \mathrm{CuPc}$ nanowires and the transition process from the $\eta$ to $\beta$-phase of $F_{16} C u P c$. The $\eta-F_{16} C u P c$ nanowires should be a metastable stable, as can be proved from the DSC curves. The key factor for the formation of $\eta$ to $\beta$-phase of $F_{16} \mathrm{CuPc}$ is the growth temperatures. The $\beta$-phase is formed at a high temperature, while the $\eta$-phase can be formed as a metastable state with the extra energy as vapours phase rapidly crystallized into crystals at room temperature. ${ }^{3}$ On the other hand, when sufficient energy is provided to the system, such as by annealing, the metastable $\eta$-phase can overcome the activation barrier and then transit to the stable $\beta$-phase. ${ }^{3,50}$

\section{Time-Dependent Density-functional Theory Calculations}

Our TDDFT calculations for the $\mathrm{F}_{16} \mathrm{CuPc}$ single molecule and the dimers ( $x$-phase) of the $\eta$ - and all the $\beta$-phases have been shown in Fig. 5(b), along with the Uv-Vis optical absorption spectra for the n-phase. ${ }^{9}$ In our TDDFT calculations for dimers, the $\mathrm{Cu}-\mathrm{Cu}$ distances are set be the related lattice constants presented in Table.1, and the inter-plane distance is set to be the experimental value, i.e., $3.25 \AA$. We have first performed a DFT calculation to compute the ground state, based on which a TDDFT calculation has been carried out to understand the experimental optical spectra.

For the calculation of the single molecule (dimer), we have computed the first 100 (150) excited states. We then present all the normalized non-zero oscillator strength as a function of the excitation energies in Fig. 5(b) along with the experimental results. The computed lowest optically accessible state for an $F_{16} \mathrm{CuPc}$ molecule is at $\lambda=600 \mathrm{~nm}$, in a good agreement with the experimental results for the Q-band that arises from the transition between the highest-occupied molecular orbital (HOMO) and lowest-unoccupied molecular orbital (LUMO). This is similar to those mentioned in our previous work. ${ }^{24,30}$ As compared with the calculation of an $\mathrm{F}_{16} \mathrm{CuPc}$ single molecule, those of the dimers show a widespreading optical spectrum from $\lambda=370 \mathrm{~nm}$ to $\lambda=760 \mathrm{~nm}$. This arises from intra-molecular exciton and inter-molecular electron hopping, leading to a mixture between intra-molecule and charge-resonance excited states. By analyzing the transitions of these excited states, we found the peaks at $\lambda=600 \mathrm{~nm}$ are dominated by the intra-molecular excitons (electron promotion happens within the same molecule), while the peaks at $\lambda=\sim 750 \mathrm{~nm}$ can be predominantly attributed to the charge-resonance state (electrons are promoted to the adjacent molecule). ${ }^{51}$ This charge-resonance state might be useful for enhancing optoelectronic devices by facilitating the charge movement via charge transfer.

Absorption spectrum of $\mathrm{F}_{16} \mathrm{CuPc}$ nanowires is shown in Fig. $5(\mathrm{~b})$. It is clear that the $\mathrm{F}_{16} \mathrm{CuPc}$ nanowires cover an even wider spectral range than that of $\mathrm{CuPc}$, from the visible region with two peaks at $\sim 620 \mathrm{~nm}$ and $\sim 784 \mathrm{~nm}$ to the near-infrared light region (NIR, $900 \mathrm{~nm}) .^{52,53}$ The blue shift in the Q-band, confirmed by our first-principles TDDFT calculations, might be 
understood as the effect of the interaction between excitons of the adjacent molecules within one column. From our calculations, we can see that the $\eta$-phase covers a slightly wider spectrum than the $\beta$-phases. Our TDDFT calculations are partially in agreement with the experimental results presented here. The remaining discrepancy can be identified between the wavelengths of $700 \mathrm{~nm}$ and $800 \mathrm{~nm}$, where the experimental intensity is comparable to that at $600 \mathrm{~nm}$, however, our TDDFT calculations show that the former is much weaker. This could be due to (i) the limited size of molecular cluster (which is only an approximation for a molecular chain) that could hinder lowering the energies, (ii) the quality of the chosen Gaussian basis set in our TDDFT calculations.

(a)

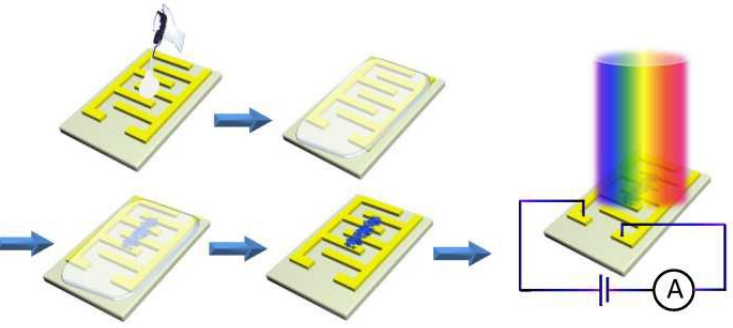

(b)
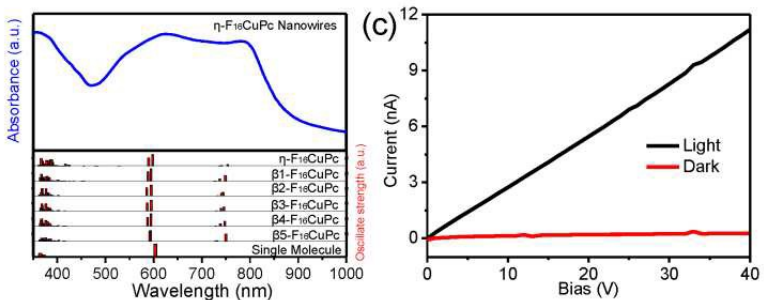

(d)

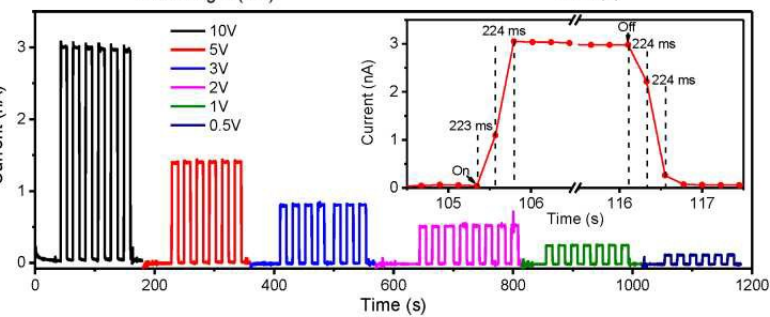

Fig. 5 (a) A schematic illustration for the photodetector device preparation. Interdigital electrodes on alumina ceramics was wetted by ethanol, then the as-prepared $\eta-\mathrm{F}_{16} \mathrm{CuPc}$ nanowires are adhered on the interdigital electrodes, the solution was eliminated in a vacuum drying oven. (b) UV-Vis absorption spectra of $F_{16} C u P c$ nanowires and all the normalized non-zero oscillator strength as a function of the excitation energies are shown. (c) The I-V curve of the photodetector device under a completely dark condition and an AM $1.5 \mathrm{G}$ solar simulator (light intensity: $100 \mathrm{~mW} \mathrm{~cm}$ ). (d) Photocurrent response measured using an AM 1.5G solar simulator (light intensity: 100 $\mathrm{mW} \mathrm{cm}$ ) at a number of bias voltages: $0.5,1,2,3,5$ and $10 \mathrm{~V}$. The inset shows the rise and fall time of the photodetector device.

\section{Photodetector devices based on the $\boldsymbol{\eta}-\mathrm{F}_{16} \mathrm{CuPc}$ nanowires}

To explore the potential of the new form of $F_{16} \mathrm{CuPc}$ nanowires crystal for device application, photodetector devices were investigated based on a facile approach, as shown in the schematic illustration in Fig. 5(a). The photograph of photodetector and its SEM image are shown in Fig. S8 (ESIt). Notice that the width of two Au electrodes is $\sim 150 \mu \mathrm{m}$, which is wider than usual; this might cause the degradation of the photodetector devices, thus deteriorating the device performance. ${ }^{54,55}$
Fig. 5(c) shows the current-voltage $(I-V)$ curves in the dark and under illumination of an AM 1.5G solar simulators (100 $\mathrm{mW} \mathrm{cm-2).} \mathrm{Notice} \mathrm{that} \mathrm{the} \mathrm{photocurrent} \mathrm{increased} \mathrm{drastically}$ under illumination. Meanwhile, the linear behavior of the curves suggests the ohmic contacts of $\mathrm{Au}$ electrodes with $\mathrm{F}_{16} \mathrm{CuPc}$ nanowires. The photocurrent responses of photodetectors were studied under illumination of an AM 1.5G solar simulators $(100 \mathrm{~mW} \mathrm{~cm}-2)$ at a number of bias voltages: $0.5,1,2,3,5$ and $10 \mathrm{~V}$ (Fig. 5(d)). With the light on, the photocurrent of the device $(\sim 3 \mathrm{nA})$ rose by almost two orders of magnitude comparing with that in the dark $(\sim 0.01$ $\mathrm{nA})$ at a bias voltage of $10 \mathrm{~V}$, which is much higher than photodetectors based on $\mathrm{F}_{16} \mathrm{CuPc}$ ribbons with $\mathrm{I}_{\text {light }} / \mathrm{I}_{\text {dark }}$ ratio of 3 measured under similar conditions, in which the $\mathrm{Cu}-\mathrm{Cu}$ distance is $4.796 \AA .{ }^{23}$ Moreover, the photodetector based on $\eta-\mathrm{F}_{16} \mathrm{CuPc}$ nanowires exhibited a fast response to the pulsed incident light as well as an excellent stability and reproducibility with a rise and fall time of $448 \mathrm{~ms}$. Several factors may result in the better performance. On one hand, the lager $\pi-\pi$ overlap between the adjacent molecules within the chain may lead to high charge transport. Meanwhile, the $\eta$-F16CuPc nanowires server as charge transport channel. On the other hand, the interdigitated electrodes used in our work may be helpful for amplifying the output current and improve device performance in some degree. ${ }^{55}$ In addition, the $n$ F16CuPc nanowires with high large surface-to-volume ratio might be another factor leading to better photon absorption to light. However, F16CuPc ribbon based phototransistor shows a rise/fall time of near $10 \mathrm{~ms}$ and $20 \mathrm{~ms}$ without the gate voltage and a maximum on/off ratio of $4.5 \times 10^{4}$ at gate voltage of $-6 \mathrm{~V}$, suggesting that the device structure will significantly influence the device performance. ${ }^{56}$ Furthermore, there is still distinct photo-response for the device even at low-bias voltages of $0.5 \mathrm{~V}$ and $1 \mathrm{~V}$.

To further investigate the properties of the photodetectors, the performance of the detector was studied under various irradiation wavelength from visible-light (589 $\mathrm{nm})$ to near-infrared $(940 \mathrm{~nm})$. As can be seen in the $I-V$ curves (Fig. S9, ESI + ), the photocurrent increased with the rising light intensity and bias voltage. The photocurrents may be influenced jointly by the different absorption coefficients of various wavelengths and by the different number of electronhole pairs excited under light illumination on the effective area of the device. The photoresponsivity $(R)$ was calculated by adopting the following formula: ${ }^{57,58}$

$$
R=\frac{I_{\text {light }}-I_{\text {dark }}}{P_{0} \times S}
$$

where $R$ is the ratio of photocurrent to the incident light intensity; $l_{\text {light }}$ and $I_{\text {dark }}$ are the electrical currents with and without light, respectively; $P_{0}$ is the irradiance light intensity, and $S$ is the effective illumination area.

The external quantum efficiency (EQE) was calculated as ${ }^{57,}$ 58 :

$$
E Q E=\frac{R \times h c}{e \lambda}
$$


where $\mathrm{h}$ the Planck constant, $c$ the velocity of light, $e$ the elemental electron charge, and $\lambda$ the wavelength of incident light.

The responsivities curves of the photodetector in Fig. 6(a) reveal the strong dependence on the bias voltage, light intensity and irradiation wavelength. The responsivities clearly indicated incremental tendency when increasing the applied voltage. Meanwhile, the responsivity decreases as increasing the light intensity, intimating the sensitivity of photodetector to weak light. Fig. 6(b) and Fig. S10(a) show the values of R and EQE with the incident light density ranging from 0.01 to $1 \mathrm{~mW}$ $\mathrm{cm}^{-2}$ with the wavelengths of $589 \mathrm{~nm}, 628 \mathrm{~nm}, 850 \mathrm{~nm}$ and $940 \mathrm{~nm}$, under a fixed bias of $10 \mathrm{~V} . R$ and EQE were found to increase with the irradiation wavelength of $589 \mathrm{~nm}, 628 \mathrm{~nm}$ and $850 \mathrm{~nm}$, as the irradiance was lowered. The R and EQE for $940 \mathrm{~nm}$ are low, which may relate to the weak absorption as shown in Fig. 5(b). Though the detector exhibited a low responsivity probably due to the device structure, its response was fast for all the wavelengths mentioned above with a rise and fall time of $448 \mathrm{~ms}$, as shown in Fig. 6(c) and (d) and Fig. S10(b)-(d).

Thus, the high performance achieved in the $\eta-F_{16} C u P c$ nanowires-based photodetector than that of $\mathrm{F}_{16} \mathrm{CuPc}$ ribbon may be attributed to the smaller $\mathrm{Cu}-\mathrm{Cu}$ distance. Given the material limitation such as the device structures and width of two $\mathrm{Au}$ electrodes, there is much room for optimization and improvement for the device performance.
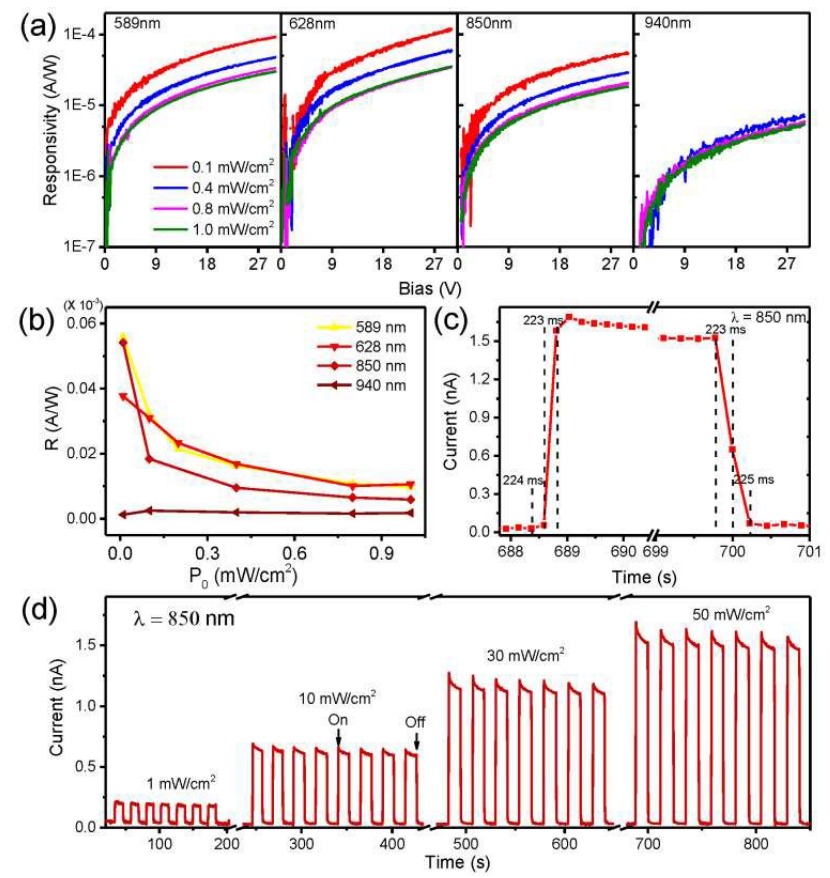

Fig. 6 (a) Responsivities of the photodetector device versus bias voltages using LED laser emitting under different light intensity and irradiance wavelengths $(589,628,850$ and $940 \mathrm{~nm})$. Responsivities of $\mathrm{F}_{16} \mathrm{CuPc}$ nanowires photodetector device versus light intensity under various wavelength illumination conditions are shown in (b). Photo response characteristics to $850 \mathrm{~nm}$ light under different densities of incident light illumination at a fixed bias of $10 \mathrm{~V}$ are shown in (c) and (d).

\section{Conclusions}

We report the new polymorph of $\mathrm{F}_{16} \mathrm{CuPc}$ nanowires fabricated by organic vapor phase deposition. The crystal structure of $\mathrm{F}_{16} \mathrm{CuPc}$ nanowires was determined, having a monoclinic unit cell and a herringbone stacking with a nearest inter- $\mathrm{Cu}$ distance (3.758 ̊̊), comparing with previous studies on $\mathrm{F}_{16} \mathrm{CuPc}$ ribbons. The $\mathrm{n}-\mathrm{F}_{16} \mathrm{CuPc}$ one-dimensional chain with the experimentally observed geometry in this work was predicted previously to possess a stronger exchange interaction. ${ }^{59}$ Moreover, morphology and phase transitions were observed during the annealing treatment of $\mathrm{F}_{16} \mathrm{CuPc}$ crystals. The $\eta$-phase of $F_{16} \mathrm{CuPc}$ is nanowire-like crystal, while $\beta$-phase is ribbon-like crystals. The phase transition from the $n$ to $\beta$-phase mainly happens between $300{ }^{\circ} \mathrm{C}$ and $500{ }^{\circ} \mathrm{C}$. The TDDFT calculations were partially in agreement with UV-Vis experimental results, probably owing to the approximation made (by using molecular dimer rather chain). Photodetector devices based on the $n-\mathrm{F}_{16} \mathrm{CuPc}$ nanowires were investigated in the dark and under light illumination. Photodetector devices show fast response even at low bias voltage of 0.5 and $1 \mathrm{~V}$ under a solar simulator with a power of $100 \mathrm{~mW} \mathrm{~cm}^{-2}$. The photocurrent of detector largely depends on the bias voltage, illumination intensity, and irradiation wavelength. The response speed of photodetector devices is fast with a rise/fall time of $448 \mathrm{~ms}$ under visible light illumination at $589 \mathrm{~nm}$ and $628 \mathrm{~nm}$ and NIR light illumination at $850 \mathrm{~nm}$ and $940 \mathrm{~nm}$. Herein, we provide a new type of organic nanowires formed by $\mathrm{F}_{16} \mathrm{CuPc}$ with large spatial $\pi-\pi$ overlaps, which could potentially enhance electro-optical properties and electron transport, thus bringing up great interest in the application of $\mathrm{F}_{16} \mathrm{CuPc}$ nanowires to electronic devices.

\section{Acknowledgements}

We gratefully acknowledge Prof. Cong Ren (Yunnan University) for helpful discussions. We thank the London Centre for Nanotechnology for the computational resources. This work was supported by the National Nature Science Foundation of China (No.11564023, No.51562019, No.31760257), and Candidates of the Young and Middle Aged Academic Leaders of Yunnan Province and program for IRTSTYN.

\section{References}

1. S. A. Choi, K. Kim, S. J. Lee, H. Lee, A. Babajanyan, B. Friedman and K. Lee, J. Lumin., 2016, 171, 149-153.

2. T. B. Fleetham, J. P. Mudrick, W. Cao, K. Klimes, J. Xue and J. Li, ACS Appl. Mater. Interfaces, 2014, 6, 7254-7259.

3. K. Xiao, R. Li, J. Tao, E. A. Payzant, I. N. Ivanov, A. A. Puretzky, W. Hu and D. B. Geohegan, Adv. Funct. Mater., 2009, 19, 3776-3780.

4. W. Deng, X. Zhang, C. Gong, Q. Zhang, Y. Xing, Y. Wu, X. Zhang and J. Jie, J. Mater. Chem. C, 2014, 2, 1314-1320.

5. B. Fu, X. Hou, C. Wang, Y. Wang, X. Zhang, R. Li, X. Shao and W. Hu, Chem. Commun., 2017, 53, 11407-11409.

6. R. Saini, A. Mahajan, R. K. Bedi, D. K. Aswal and A. K. Debnath, Sens. Actuators, B, 2014, 203, 17-24. 
7.

R. Saini, A. Mahajan, R. K. Bedi, D. K. Aswal and A. K. Debnath, RSC Adv., 2014, 4, 15945-15951.

8. H. K. Moon, M. Son, J. E. Park, S. M. Yoon, S. H. Lee and H. C. Choi, NPG Asia Materials, 2012, 4, e12.

9. A. Hoshino, Y. Takenaka and H. Miyaji, Acta Crystallographica Section B Structural Science, 2003, 59, 393-403.

10. X. He, G. Zhu, J. Yang, H. Chang, Q. Meng, H. Zhao, X. Zhou, S. Yue, Z. Wang, J. Shi, L. Gu, D. Yan and Y. Weng, Sci. Rep., 2015, 5, 17076.

11. M. Serri, W. Wu, L. R. Fleet, N. M. Harrison, C. F. Hirjibehedin, C. W. Kay, A. J. Fisher, G. Aeppli and S. Heutz, Nat. Commun., 2014, 5, 3079.

12. W. Wu, A. J. Fisher and N. M. Harrison, Phys. Rev. B, 2011, 84.

13. H. Wang, S. Mauthoor, S. Din, J. A. Gardener, R. Chang, M. Warner, G. Aeppli, D. W. McComb, M. P. Ryan, W. Wu, A. J. Fisher, M. Stoneham and S. Heutz, ACS Nano, 2010, 4, 3921-3926.

14. S. L. Lai, M. Y. Chan, M. K. Fung, C. S. Lee and S. T. Lee, J. Appl. Phys., 2007, 101.

15. Q. Tang, H. Li, Y. Liu and W. Hu, J. Am. Chem. Soc., 2006 , 128, 14634-14639.

16. S. M. Yoon, S. J. Lou, S. Loser, J. Smith, L. X. Chen, A. Facchetti and T. J. Marks, Nano Lett., 2012, 12, 63156321.

17. Z. Bao, A. J. Lovinger and J. Brown, J. Am. Chem. Soc., 1998, 120, 207-208.

18. H. Jiang, K. J. Tan, K. K. Zhang, X. Chen and C. Kloc, J. Mater. Chem., 2011, 21, 4771.

19. H. Jiang, J. Ye, P. Hu, F. Wei, K. Du, N. Wang, T. Ba, S. Feng and C. Kloc, Sci. Rep., 2014, 4.

20. Y. Kuzumoto, H. Matsuyama and M. Kitamura, Japanese Journal of Applied Physics, 2014, 53.

21. P. A. Pandey, L. A. Rochford, D. S. Keeble, J. P. Rourke, T. S. Jones, R. Beanland and N. R. Wilson, Chem. Mater., 2012, 24, 1365-1370.

22. D. G. de Oteyza, E. Barrena, J. O. Osso, S. Sellner and H. Dosch, J. Am. Chem. Soc., 2006, 128, 15052-15053.

23. S. M. Yoon, H. J. Song, I.-C. Hwang, K. S. Kim and H. C. Choi, Chem. Commun., 2010, 46, 231-233.

24. X. Ji, T. Zou, H. Gong, Q. Wu, Z. Qiao, W. Wu and H. Wang, Cryst. Res. Technol., 2016, 51, 154-159.

25. B. N. Mbenkum, E. Barrena, X. Zhang, M. Kelsch and H. Dosch, Nano Lett., 2006, 6, 2852-2855.

26. A. D. Becke, The Journal of Chemical Physics, 1993, 98, 5648-5652.

27. R. Ditchfield, W. J. Hehre and J. A. Pople, The Journal of Chemical Physics, 1971, 54, 724-728.

28. M. Frisch, G. Trucks, H. Schlegel, G. Scuseria, M. Robb, J. Cheeseman, J. Montgomery Jr, T. Vreven, K. Kudin and J. Burant, Inc., Pittsburgh, PA, 2003.

29.

F. A. Buot, J. Dobson, R. Dreizler, E. Engel, E. Gross, M. Petersilka and A. Rajagopal, Density Functional Theory II: Relativistic and Time Dependent Extensions, Springer, 1996.

30. X. Wang, W. Wu, H. Ju, T. Zou, Z. Qiao, H. Gong and H. Wang, Mater. Res. Express, 2016, 3, 125002.

31. W. Wu, N. Harrison and A. Fisher, Phys. Rev. B, 2013, 88, 024426.

32. W. Wu, A. Kerridge, A. H. Harker and A. J. Fisher, Phys. Rev. B, 2008, 77.
33.

34.

J. Muscat, A. Wander and N. M. Harrison, Chem. Phys. Lett., 2001, 342, 397-401.

F. Illas, I. Moreira, x000E, P. R. rio, C. de Graaf and V. Barone, Theoretical Chemistry Accounts: Theory, Computation, and Modeling (Theoretica Chimica Acta), 2000, 104, 265-272.

35. R. E. Stratmann, G. E. Scuseria and M. J. Frisch, The Journal of Chemical Physics, 1998, 109, 8218-8224.

36. M. Petersilka, U. J. Gossmann and E. K. Gross, Phys. Rev. Lett., 1996, 76, 1212-1215.

37. W. Y. Tong, A. B. Djurisic, M. H. Xie, A. C. M. Ng, K. Y. Cheung, W. K. Chan, Y. H. Leung, H. W. Lin and S. Gwo, J. Phys. Chem. B, 2006, 110, 17406-17413.

38. U. K. Ghorai, S. Das, S. Saha, N. Mazumder, D. Sen and K. K. Chattopadhyay, Dalton Trans., 2014, 43, 9260-9266.

39. S. Das, S. Maiti, S. Saha, N. S. Das and K. K. Chattopadhyay, J. Nanosci. Nanotechnol., 2013, 13, 2722 2728.

40. Q.-H. Wu, G. Hong and S. T. Lee, Org. Electron., 2013, 14 542-547.

41. http://srdata.nist.gov/xps/EngElmSrchQuery.aspx?EType= PE\&CSOpt=Retri_ex_dat\&Elm $=C$

42. C. Kleimann, B. Stadtmueller, S. Schroeder and C. Kumpf, J. Phys. Chem. C, 2014, 118, 1652-1660.

43. U. Kumar Ghorai, S. Saha, N. Mazumder, N. S. Das, D. Banerjee, D. Sen and K. K. Chattopadhyay, RSC Adv., 2015, 5, 23847-23854.

44. D. Yan, Y. Feng and C. Wang, Progress in Natural Science: Materials International, 2013, 23, 543-548.

45. E. DeOliveira, C. R. Neri, A. O. Ribeiro, V. S. Garcia, L. L. Costa, A. O. Moura, A. G. Prado, O. A. Serra and Y. lamamoto, J. Colloid Interface Sci., 2008, 323, 98-104.

46. M. Ashida, N. Uyeda and E. Suito, J. Cryst. Growth, 1971, 8, 45-56.

N. Uyeda, J. Appl. Phys., 1972, 43, 5181.

48. J. E. Anthony, A. Facchetti, M. Heeney, S. R. Marder and X. Zhan, Adv. Mater., 2010, 22, 3876-3892.

49. W. Wu, Y. Liu and D. Zhu, Chem. Soc. Rev., 2010, 39, 14891502.

J. H. Beynon and A. R. Humphries, Trans. Faraday Soc., 1955, 51, 1065.

O. Bilsel, J. Rodriguez, S. N. Milam, P. A. Gorlin, G. S. Girolami, K. S. Suslick and D. Holten, J. Am. Chem. Soc. 1992, 114, 6528-6538.

52. E. Kol'tsov, T. Basova, P. Semyannikov and I. Igumenov, Mater. Chem. Phys., 2004, 86, 222-227.

53. T. Basova, E. Kol'tsov, A. Hassan, A. Tsargorodskaya, A Ray and I. Igumenov, physica status solidi (b), 2005, 242, 822-827.

54. H. Wang, W. Deng, L. Huang, X. Zhang and J. Jie, ACS Appl. Mater. Interfaces, 2016, 8, 7912-7918.

55. A. L. Briseno, S. C. Mannsfeld, C. Reese, J. M. Hancock, Y. Xiong, S. A. Jenekhe, Z. Bao and Y. Xia, Nano Lett., 2007, 7, 2847-2853.

56. Q. Tang, L. Li, Y. Song, Y. Liu, H. Li, W. Xu, Y. Liu, W. Hu and D. Zhu, Adv. Mater., 2007, 19, 2624-+.

J. Miao, W. Hu, N. Guo, Z. Lu, X. Liu, L. Liao, P. Chen, T. Jiang, S. Wu, J. C. Ho, L. Wang, X. Chen and W. Lu, Small, 2015, 11, 936-942.

58. L. Li, P. Wu, X. Fang, T. Zhai, L. Dai, M. Liao, Y. Koide, H. Wang, Y. Bando and D. Golberg, Adv. Mater., 2010, 22 3161-3165. 
59. W. Wu, L. A. Rochford, S. Felton, Z. Wu, J. L. Yang, S. Heutz, G. Aeppli, T. S. Jones, N. M. Harrison and A. J. Fisher, J. Appl. Phys., 2013, 113. 